\title{
Design of a Linear Synchronous Generator and Examination of the Driving Range for a Free-Piston Engine Linear Generator System
}

\author{
Yuichiro Yamanaka*a) \\ Mitsuhide Sato, ${ }^{*, * *}$ \\ Yinggang $\mathrm{Bu}^{*}$
}

\author{
Student Member, \\ Student Member, \\ Senior Member,
}

\author{
Masami Nirei ** \\ Hironobu Murata* \\ Tsutomu Mizuno*
}

\author{
Senior Member \\ Non-member \\ Senior Member
}

(Manuscript received Oct. 26, 2017, revised March 14, 2018)

\begin{abstract}
A free-piston engine linear generator (FPEG) system is a linear generator, which generates electricity when a free piston reciprocates the combustion thrust produced by internal combustion. It is expected that this system can be applied to hybrid vehicles. In an FPEG system, the high combustion energy is instantly added to a free piston. Nevertheless, it is difficult for a linear synchronous generator (LSG) to convert combustion energy into electric energy by using the output of the LSG given the limit of the inverter capacity. Hence, it is necessary for an LSG to convert combustion energy into electric energy while distributing the combustion energy in one stroke. Moreover, if an LSG is driven at high velocity and high thrust within the limit of an inverter capacity, then the LSG converts the high combustion energy into electric energy. In this study, we propose a configuration of an LSG with a typical output of $10 \mathrm{~kW}$ and a generation efficiency of $97 \%$ for an FPEG, and we evaluate its static thrust and magnetic flux density distribution using finite element method (FEM) analysis. Moreover, we examine the driving range of the LSG for an FPEG system.
\end{abstract}

Keywords: FEM analysis, free-piston engine, HEV system, Linear Synchronous Generator, magnetic flux density distribution, static thrust distribution

\section{Introduction}

Automobiles have contributed to improvements in standards of living and economic growth. However, environmental problems including air pollution and global warming that are caused by automotive vehicles continues to pose serious issues-although reduced by the increase of hybrid electrical vehicles (HEVs) are still serious. To solve this environmental issue, it is essential to develop a new power train and HEV system to improve the overall efficiency of automobiles ${ }^{(1)-(4)}$. Therefore, this study proposes an FPEG system.

An FPEG system generates electricity by using the free piston that reciprocates combustion thrust, and it possesses several important characteristics. The system experiences only small mechanical losses due to friction because it does not possess a crank mechanism. Additionally, it is possible for an FPEG system to exhibit high-efficiency movement due to a free piston that drive at resonant frequency. Furthermore, an FPEG system freely changes the stroke and compression ratio. Therefore, the thermal efficiency rises when compare with a conventional engine ${ }^{(5)}$. As mentioned above, an FPEG system is expected to exhibit higher efficiency when

a) Correspondence to: Yuichiro Yamanaka. E-mail: 17w2099d@ shinshu-u.ac.jp

* Faculty of Engineering, Shinshu University 4-17-1, Wakasato, Nagano-city, Nagano 380-8553, Japan

** National Institute of Technology, Nagano College 716, Tokuma, Nagano-city, Nagano 381-8550, Japan

*** Nagano Prefectural Institute of Technology

813-8, Shimonogo, Ueda-city, Nagano 386-1211, Japan compared to a hybrid systems and current HEV systems ${ }^{(5)-(7)}$.

An FPEG system generates electricity by using the combustion thrust. Furthermore, high combustion energy is instantly added to a free-piston. Nevertheless, it is difficult for a linear synchronous generator (LSG) to convert combustion energy into electric energy by using the output of the LSG given the limit of the inverter capacity. Hence, it is necessary for an LSG to convert combustion energy into electric energy while distributing combustion energy in one-stroke. Moreover, if an LSG is driven at high-velocity and high-thrust in limit of an inverter capacity, then an LSG converts high combustion energy into electric energy. Thus, an LSG for an FPEG system satisfies the following requirements.

1) High thrust and high generation efficiency

2 ) Extension of the driving range

In this paper, with the aim of designing an LSG for FPEG system, described the following points regarding the FPEG system:

(1) Basic structure of the FPEG system

(2) Examination of driving range of the LSG

\section{Basic Principle of the FPEG System}

Figure 1 shows the physical models of the FPEG system. The free-piston moves to the bottom dead center by the combustion thrust at which point the thrust of the gas spring chamber increase. The piston is moved to the top dead center by the thrust of the gas spring chamber. This movement is repeated to reciprocate the free-piston. At this point, the equation of motion for the FPEG system is given by 


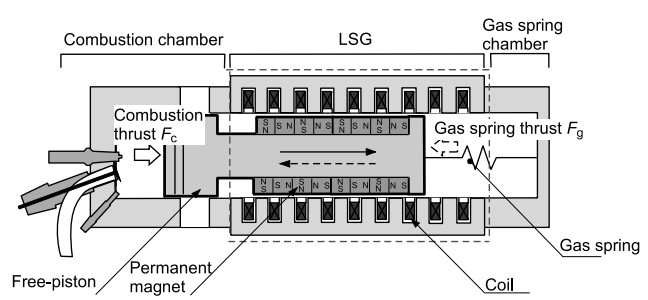

(a) Mechanical model

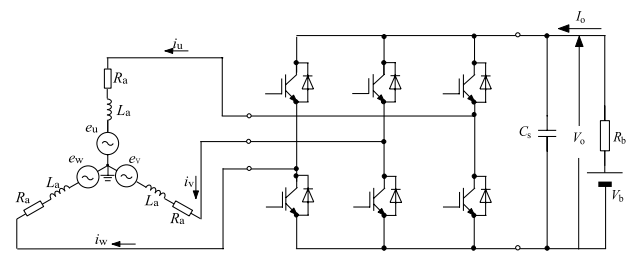

(b) Circuit model

Fig. 1. Physical models of FPEG system

Table 1. Target specifications of LSG

\begin{tabular}{|c|c|c|c|}
\hline Item & Symbol & Value & (unit) \\
\hline Generating efficiency & $\eta_{\mathrm{e}}$ & 95 & $(\%)$ \\
\hline $\begin{array}{l}\text { Resistance of } \\
\text { armature coil }\end{array}$ & $R_{\mathrm{a}}$ & 200 & $(\mathrm{~m} \Omega /$ phase $)$ \\
\hline Mass of mover & $m$ & 5 & $(\mathrm{~kg})$ \\
\hline Maximum static thrust & $F$ & 4.0 & $(\mathrm{kN})$ \\
\hline Coil space factor & $\zeta$ & 70 & $(\%)$ \\
\hline $\begin{array}{l}\text { Maximum armature } \\
\text { current }\end{array}$ & $I$ & 200 & (A) \\
\hline $\begin{array}{l}\text { Maximum flux } \\
\text { density }\end{array}$ & $B_{\mathrm{m}}$ & 1.8 & (T) \\
\hline Drive frequency & $f$ & 20 & $(\mathrm{~Hz})$ \\
\hline
\end{tabular}

$m \ddot{x}=F_{\mathrm{c}}-F_{1}-F_{\mathrm{g}}-F_{\mathrm{r}}(\mathrm{N})$

where $m$ is the mass of the mover, $x$ is the piston position, $F_{\mathrm{c}}$ is the combustion thrust, $F_{1}$ is the thrust of generation braking, $F_{\mathrm{g}}$ is the thrust of the gas spring and $F_{\mathrm{r}}$ is the friction thrust of the piston.

The free-piston is reciprocated, and thus the back electromotive force occurs based on Faraday's law of induction. The generated electric current charge the battery through an inverter.

Currently, the system controls the d-axis current to $0 \mathrm{~A}$ by using the pulse width modulation (PWM) inverter to improve the generation efficiency.

\section{Design of the LSG}

3.1 Method of Examination Table 1 shows the target specifications of the LSG. The target of the static thrust is defined as the thrust necessary to stably move a free-piston. The thrust was calculated in the simulation. When a core is magnetically saturated, the difference in the magnetic permeability between the core and the gap becomes small. Additionally, the thrust does not increase even if the armature current increase ${ }^{(8)}$. Therefore, the objective of the maximum magnetic flux density involves to not exceeding the saturated magnetic flux density of the non-oriented electrical steel sheets that are used as the material of the cores.

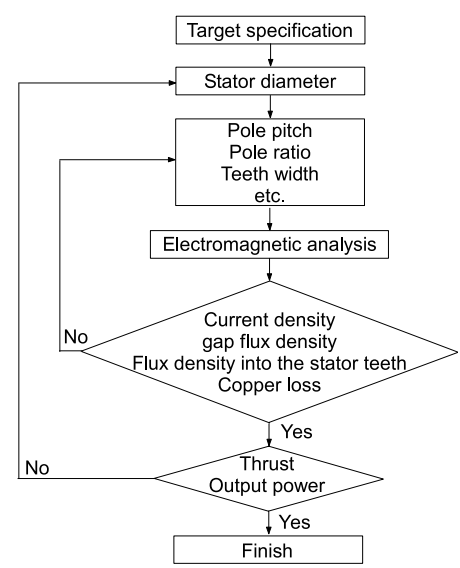

Fig. 2. Design flow of the LSG

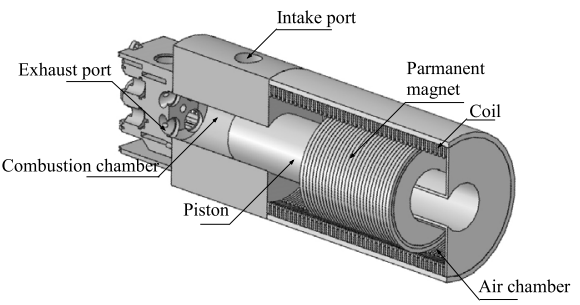

(a) Perspective view

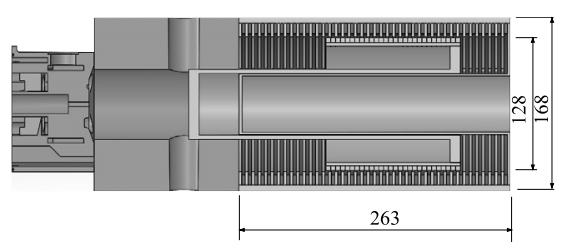

(b) Sectional view

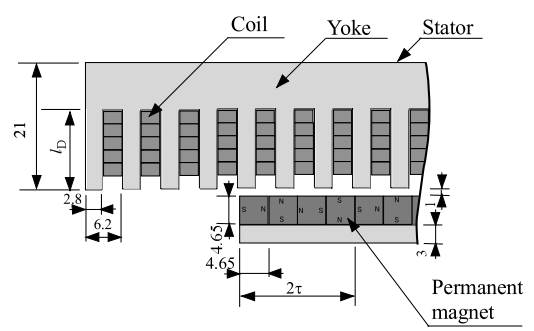

(c) Enlarged view

Fig. 3. Basic structures of FPEG system (unit: mm)

Furthermore, the objective space factor for the coils is $70 \%$ when insulation processing is considered.

Figure 2 shows the design flow of the LSG. We designed the LSG by following the design flow. Subsequently, the process of the design is as the follow. [1] Selection of the external dimensions of the LSG from the target of the output. [2] Selection of the pole pitch, number of poles, and slot combination. [3] Selection of the magnetomotive force of the permanent magnet. [4] Selection of the magnetic resistance to satisfy the target thrust. As stated above, the process is repeated to design the LSG.

3.2 Basic Structure of the LSG Figure 3 shows the basic structure of the LSG. Table 2 shows the specifications of the LSG. The stator comprises of a yoke and coils, and the mover comprises of a yoke and a permanent magnet. Therefore, the LSG is a magnet- movlable model. Additionally, the number of slots and the number of pole pairs are 42 and 
Table 2. Specifications of the LSG

\begin{tabular}{|c|c|c|c|}
\hline Item & Symbol & Value & (unit) \\
\hline External dimensions & - & $168 \times 263$ & $(\mathrm{~mm})$ \\
\hline Internal dimensions & & $128 \times 130$ & $(\mathrm{~mm})$ \\
\hline Mass of mover & $m$ & 5.25 & $(\mathrm{~kg})$ \\
\hline Number of slots & $N_{\mathrm{s}}$ & 42 & \\
\hline Depth of slot & $l_{\mathrm{D}}$ & 13 & $(\mathrm{~mm})$ \\
\hline Width of slot & $s_{\mathrm{s}}$ & 3.4 & $(\mathrm{~mm})$ \\
\hline Number of poles & $P$ & 14 & \\
\hline Pole pitch & $2 \tau$ & 18.6 & $(\mathrm{~mm})$ \\
\hline Width of coil & $w_{\mathrm{c}}$ & 3 & $(\mathrm{~mm})$ \\
\hline Thickness of coil & $t_{\mathrm{c}}$ & 2 & $(\mathrm{~mm})$ \\
\hline Number of coil turns & $N$ & 5 & \\
\hline Coil space factor & $\zeta$ & 67.8 & $(\%)$ \\
\hline Resistance of armature coil & $R_{\mathrm{a}}$ & 108 & $(\mathrm{~m} \Omega /$ phase $)$ \\
\hline Inductance of armature coil & $L_{\mathrm{a}}$ & 1.8 & $(\mathrm{mH} /$ phase $)$ \\
\hline
\end{tabular}

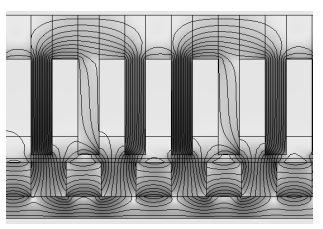

(a) $I=0 \mathrm{~A}$

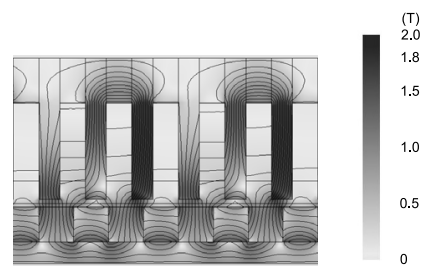

(b) $I=200 \mathrm{~A}$
Fig. 4. Magnetic flux density distribution of LSG

7, respectively. Therefore, the LSG is also classified as an integral-slot model. The winding coefficient of the slot combination is 0.866 . The coil features intensive winding, moreover, the coils features ring form shape. and this has the following advantages

1 ) It facilitates production.

2 ) It increases the coil space factor.

3 ) The copper loss is expected to decrease due to no coil ends.

Additionally, the coil wind-up spiral was shaped to fit into a single slot, which hides the coil end. Furthermore, a rectangular wire is adopted to increase the coil space factor, and the conductor cross section of the rectangular wire is selected by setting the limit of the current density while considering consecutive driving. The stator is divided into three parts to facilitate production. As a result, the armature resistance per phase is $108 \mathrm{~m} \Omega$ per phase, which satisfies the target of less than $200 \mathrm{~m} \Omega$.

The permanent magnet use sintered neodymium magnet to enhance the magnetic loading. Moreover, the permanent magnet is lined to constitute a Halbach array and it can increase the air gap flux density.

3.3 Simulation Figure 4 shows the magnetic flux density of the LSG when the maximum armature current corresponds to $0 \mathrm{~A}$ and $200 \mathrm{~A}$. When the armature current is $0 \mathrm{~A}$,

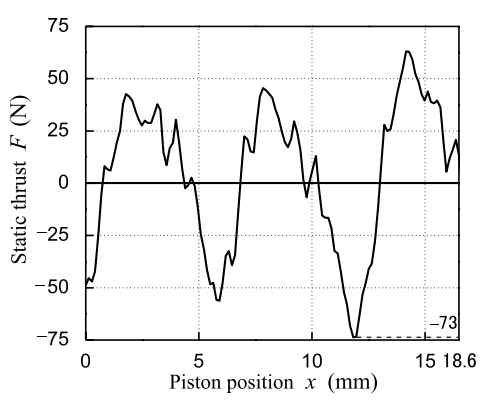

(a) The detent thrust.

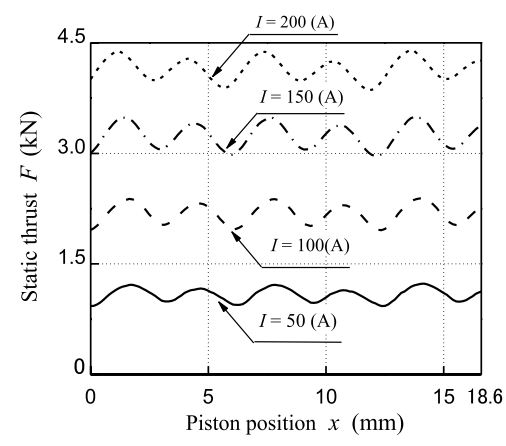

(b) Static thrust $(I=50,100,150,200 \mathrm{~A})$

Fig. 5. Static thrust of LSG

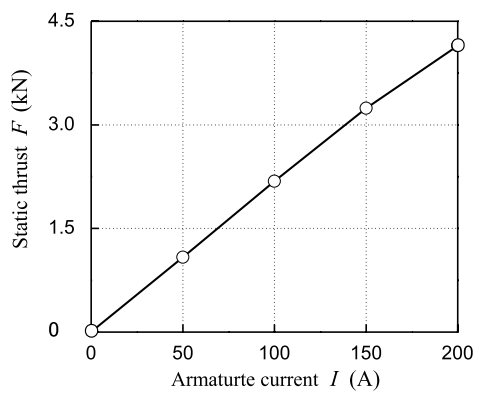

Fig. 6. Static thrust vs. current characteristic of LSG

the end of the armature teeth is magnetically saturated, and the magnetic flux density is $2.2 \mathrm{~T}$. However, in the center of the armature teeth, the magnetic flux density is as high as the allowable magnetic flux density.

Because the magnetic flux density distribution in $200 \mathrm{~A}$, which is lower than the prescribed maximum armature current of the FPEG system chosen to be less than the saturated magnetic flux distribution of non-oriental electromagnetic steel sheets. Thus, the LSG is confirmed to work stably.

Figure 5 shows the static thrust distribution toward each armature current for the pole pitch. When the armature current is $0 \mathrm{~A}$, the detent thrust assumes a maximum value of $73 \mathrm{~N}$. Moreover, the static thrust is constant for any mover position.

Figure 6 shows the static thrust versus the armature current that maintains a linear trend up to $200 \mathrm{~A}$, which corresponds to the prescribed maximum armature current for the FPEG system. The achieved static thrust is $2.5 \mathrm{kN}$, which is the target value necessary for stable operation. The calculated thrust constant, it is $22 \mathrm{~N} / \mathrm{A}$, can be used to calculate the motor constant. The motor constant $K_{\mathrm{m}}$ is given by

$$
K_{\mathrm{m}}=\frac{K_{\mathrm{f}}}{\sqrt{R_{\mathrm{a}}}}(\mathrm{N} / \sqrt{\mathrm{W}}) .
$$

where $K_{\mathrm{f}}$ is the thrust constant and $R_{\mathrm{a}}$ is the armature 


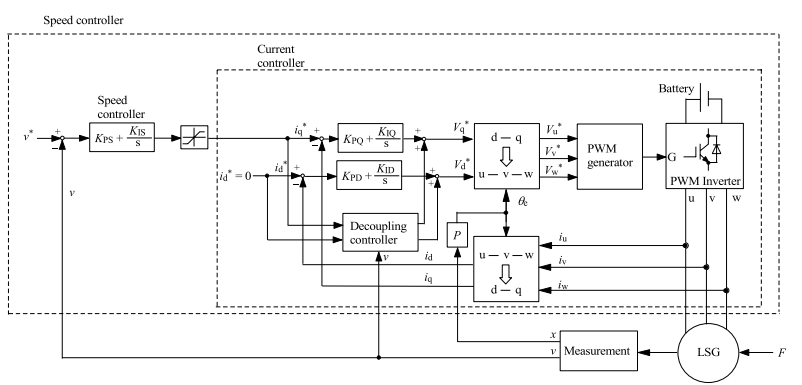

Fig. 7. Block diagram of LSG

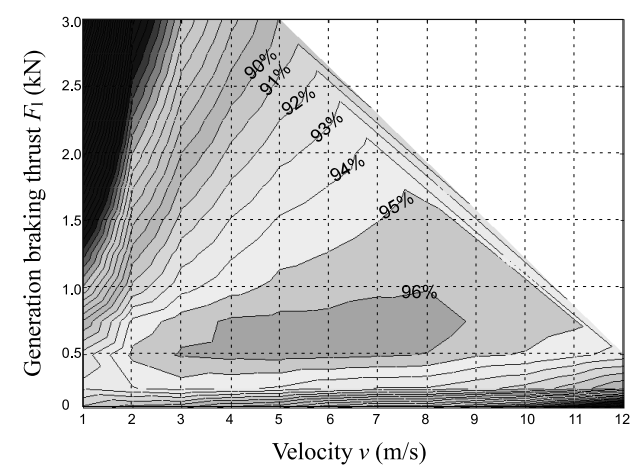

Fig. 8. Generation efficiency map of $\operatorname{LSG}\left(V_{\mathrm{dc}}=500 \mathrm{~V}\right)$

resistance.

The resulting calculating value for $K_{\mathrm{m}}$ is $66.9 \mathrm{~N} / \sqrt{\mathrm{W}}$.

From the above calculations, the system achieves the targets for thrust.

Subsequently, generation efficiency is examined. Figure 7 shows at block diagram to examine the generation efficiency of the LSG. The LSG is controlled by the PI controller of velocity and electric current by using the PWM inverter. The electric current controller uses a d-axis current zero controller and a decoupling controller. The generator efficiency is calculated from the output current and the output voltage when the piston velocity is in a steady state. At this point, the generation efficiency $\eta_{\mathrm{e}}$ is given by

$$
\begin{aligned}
\eta_{\mathrm{e}} & =\frac{I_{\mathrm{o}} \times V_{\mathrm{o}}}{F_{\mathrm{e}} \times v} \\
& =\frac{P_{\mathrm{o}}}{P_{\mathrm{o}}+Q_{\mathrm{c}}+Q_{\mathrm{i}}}
\end{aligned}
$$

where $I_{\mathrm{o}}$ is output current of inverter, $V_{\mathrm{o}}$ is output voltage of Inverter, $F_{\mathrm{e}}$ is external thrust, $P_{\mathrm{o}}$ is output electric power, $Q_{\mathrm{c}}$ is copper loss and $Q_{\mathrm{i}}$ is iron loss,

Thus iron loss is given by

$$
\begin{aligned}
Q_{\mathrm{i}} & =Q_{\mathrm{e}}+Q_{\mathrm{h}} \\
& =k_{\mathrm{e}} f_{\mathrm{e}}{ }^{2} B_{\mathrm{m}}{ }^{2}+k_{\mathrm{h}} f_{\mathrm{e}} B_{\mathrm{m}}{ }^{1.6}
\end{aligned}
$$

where $Q_{\mathrm{e}}$ is eddy current loss, $Q_{\mathrm{h}}$ is hysteresis loss, $k_{\mathrm{e}}$ is proportional constant, $f_{\mathrm{e}}$ is frequency of the electric current, $B_{\mathrm{m}}$ is maximum magnetic flux density, and $k_{\mathrm{h}}$ is proportional constant.

Figure 8 shows the generator efficiency map for the LSG. A high generation efficiency exceeding $96 \%$ is provided in the low-thrust and high-velocity domain. Because only a small amount of generation braking thrust is necessary at low thrusts, and thus the electric current called off the coil
Table 3. Preconditions of the examination

\begin{tabular}{l|c|rl}
\hline Item & Symbol & Value & (unit) \\
\hline Combustion energy & $P_{\mathrm{c}}$ & 4 & $(\mathrm{~kW})$ \\
\hline Driving frequency & $f$ & 20 & $(\mathrm{~Hz})$ \\
\hline Piston stroke & $s$ & 100 & $(\mathrm{~mm})$ \\
\hline DC shrink voltage & $V_{\mathrm{dc}}$ & 500 & $(\mathrm{~V})$ \\
\hline
\end{tabular}

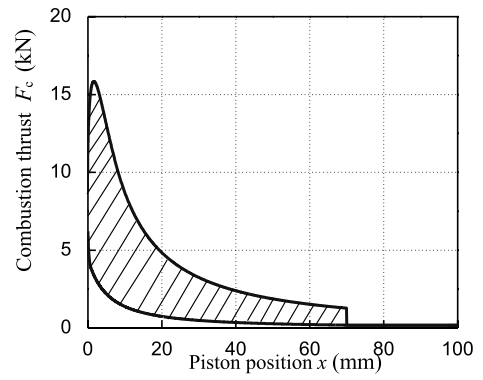

Fig. 9. Combustion thrust vs. position characteristic

is small and copper loss decreases. Additionally, the ratio of the copper loss increases because the output electric power decreases in the low-velocity domain. Furthermore, the ratio of copper loss decreases in the high-velocity domain, output electric power ratio increases, and generation efficiency improves.

From the above conclusions, the following points are obtained for control methods to produce high generating efficiencies:

(1) Avoid generating electricity in the low-velocity domain

(2) Generate electricity based on the generator efficiency map only at high-efficiency points.

\section{Examination of the Driving Range of the LSG}

An FPEG system generates electricity by using the combustion thrust. Moreover, high combustion energy is instantly added to a free-piston. However it is difficult for an LSG to convert combustion energy into electric energy by the output of the LSG and limits of the inverter capacity. Therefore, it is necessary for an LSG to convert combustion energy into electric energy while distributing combustion energy in onestroke. Additionally, an LSG converts high combustion energy into electric energy if a LSG drives high-velocity and high-thrust at the limit of inverter capacity.

Therefore, we examine the driving range of the LSG at the limit of the inverter capacity.

4.1 Condition of the Examination Prior to performing the examination, preconditions are set to easily perform the same. Table 3 shows the preconditions of the examination, and Fig. 9 shows Combustion thrust versus piston position characteristic. Combustion energy $P_{\mathrm{c}}$ corresponds to the output of $4 \mathrm{~kW}$ by the combustion in the combustion chamber. The combustion hysteresis corresponds to the curve in Fig. 9. Subsequently, the free-piston is involve an assumption about sine wave driving in which driving frequency $f$ is $20 \mathrm{~Hz}$ and the piston stroke $s$ is $100 \mathrm{~mm}$. The control system is composed of a PI controller of velocity and an electric current that uses PWM invertor is similar to that in Fig. 7. 
Moreover, the PWM inverter uses the comparison with a triangular wave. The DC shrink voltage of the inverter is set as $500 \mathrm{~V}$.

4.2 Influence of Pole Pitch At the setout, we examine the limit of the voltage. At the PWM control using comparison with triangular wave, the maximum armature voltage $V_{\text {amax }}$ is given by

$$
V_{\mathrm{amax}}=\frac{1}{2} V_{\mathrm{dc}} \cdot \sqrt{\frac{3}{2}}=0.612 V_{\mathrm{dc}} \quad(\mathrm{V}) \cdots \cdots \cdots
$$

Then, equation (5) holds that modulation factor of the PWM invertor is 1. Additionally, from equation (5), the maximum current phasor $I_{\mathrm{amax}}$ is given by

$$
I_{\mathrm{amax}}=\frac{V_{\mathrm{amax}}}{R_{\mathrm{a}}+\omega_{\mathrm{e}} L_{\mathrm{a}}}
$$

where $\omega_{\mathrm{e}}$ is the electric angular velocity.

Furthermore, the electric angular velocity $\omega_{\mathrm{e}}$ is given by

$$
\omega_{\mathrm{e}}=\frac{\pi}{\tau} v \quad(\operatorname{rad} / \mathrm{s}) \ldots \ldots \ldots \ldots \ldots \ldots \ldots \ldots \ldots \ldots \ldots \ldots \ldots
$$

Based on the equation (6) and (7), it is necessary to expand the pole pitch to expand driving range of the LSG in highvelocity domain. At the point, the combustion energy output $4 \mathrm{~kW}$, and thus the LSG should generate $800 \mathrm{~J}$ in one-stroke. Therefore, we examine the thrust necessary to generate $800 \mathrm{~J}$ when the piston velocity is maximum. The necessary thrust when the piston velocity is maximum is given by

$$
F=\frac{P_{\mathrm{c}} \cdot 2 s}{v_{\max } \cdot\left(\frac{1}{f}\right)}
$$

where $v_{\max }$ is the maximum piston velocity.

From the equation (8), when the free-piston is driven the sine wave which driving frequency is $20 \mathrm{~Hz}$ and piston stroke is $100 \mathrm{~mm}$, The necessary thrust in the maximum piston velocity $6.28 \mathrm{~m} / \mathrm{s}$ is $2547 \mathrm{~N}$. However, this thrust is not satisfactory as shown in Fig. 7. Hence, we examine the change in the driving range when the pole pitch is modified.

4.3 Examination of Pole Pitch Table 4 shows the specifications of the LSG in which the pole pitch is modified. Each model is modified the pole pitch $21.6 \mathrm{~mm}$ and $26.1 \mathrm{~mm}$ which is 1.2 times and 1.4 times as long as $18.6 \mathrm{~mm}$ on condition that external dimensions of stator and mover is equation the LSG which $2 \tau$ is $18.6 \mathrm{~mm}$. Subsequently, from equation (6), when the piston velocity is $6.28 \mathrm{~m} / \mathrm{s}$, the thrusts of the LSG in which $2 \tau$ corresponds to $21.6 \mathrm{~mm}$ and $26.1 \mathrm{~mm}$ are $2605 \mathrm{~N}$ and $2741 \mathrm{~N}$, respectively.

4.4 Result of Simulation Figure 10 shows the static thrust versus armature current characteristic of the LSG which pole pitch is modified. The static thrust of each LSG maintains a linear trend up to $200 \mathrm{~A}$, and the achieved static thrust is $2.5 \mathrm{kN}$. However, the thrust constant of the LSG which $2 \tau$ is $21.6 \mathrm{~mm}$ and $26.1 \mathrm{~mm}$ are 18.0 N/A and 14.7 N/A, respectively. Because to expand the pole pitch on condition that external dimensions of stator is equation the LSG which $2 \tau$ is $18.6 \mathrm{~mm}$, number of slots is decreased. Thus, the resulting calculating value for $K_{\mathrm{m}}$ of the LSG which

\begin{tabular}{|c|c|c|c|}
\hline Item & Symbol & $2 \tau=21.6 \mathrm{~mm}$ & $2 \tau=26.1 \mathrm{~mm}$ \\
\hline Number of slots & $N_{\mathrm{s}}$ & 36 & 30 \\
\hline Depth of slot (mm) & $l_{\mathrm{D}}$ & 13 & 13 \\
\hline Width of slot $(\mathrm{mm})$ & $s_{\mathrm{s}}$ & 3.4 & 5.0 \\
\hline Number of poles $(\mathrm{mm})$ & $P$ & 12 & 10 \\
\hline Pole pitch & $2 \tau$ & 21.6 & 26.1 \\
\hline Width of coil (mm) & $w_{\mathrm{c}}$ & 3.5 & 4.6 \\
\hline Thickness of coil (mm) & $t_{\mathrm{c}}$ & 2 & 2 \\
\hline Number of coil turns & $N$ & 5 & 5 \\
\hline Coil space factor (\%) & $\zeta$ & 67.8 & 67.8 \\
\hline $\begin{array}{l}\text { Resistance of armature coil } \\
(\mathrm{m} \Omega / \text { phase })\end{array}$ & $R_{\mathrm{a}}$ & 66 & 42 \\
\hline $\begin{array}{l}\text { Inductance of armature coil } \\
(\mathrm{mH} / \text { phase) }\end{array}$ & $L_{\mathrm{a}}$ & 1.7 & 1.6 \\
\hline
\end{tabular}
$2 \tau$ corresponds to $21.6 \mathrm{~mm}$ and $26.1 \mathrm{~mm}$ are $70.0 \mathrm{~N} / \sqrt{\mathrm{W}}$ and
Table 4. Specifications of the LSG (The pole pitch is modified)

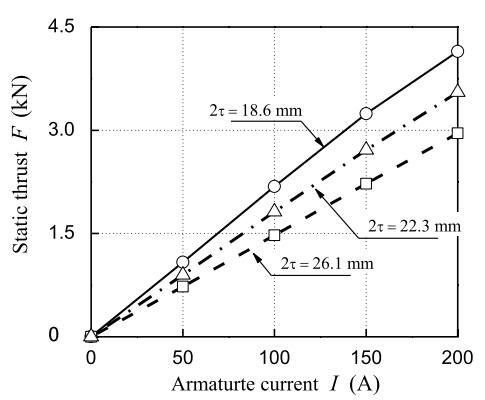

Fig. 10. Static thrust vs. current characteristic of LSG

$71.8 \mathrm{~N} / \sqrt{\mathrm{W}}$, respectively and they improve by $4 \%$ and $7 \%$, respectively as high as the LSG which $2 \tau$ is $18.6 \mathrm{~mm}$. This is because the armature resistance decreases due to the decrease in the number of slots.

Figure 11 shows the generation efficiency map of the LSG in which pole pitch is modified. The maximum generation efficiency of each LSG is $95 \%$, and decreases by $1 \%$ when compared with the LSG in which $2 \tau$ is $18.6 \mathrm{~mm}$. However the limits of the driving range are more extensive than the LSG in which $2 \tau$ is $18.6 \mathrm{~mm}$ because the impedance of the high-velocity domain decreases since pole pitch expands and the maximum current phasor increases. Therefore, when the piston velocity is $6.28 \mathrm{~m} / \mathrm{s}$, the thrust of the LSG in which $2 \tau$ is $21.6 \mathrm{~mm}$ and $26.1 \mathrm{~mm}$ are $2687 \mathrm{~N}$ and $2750 \mathrm{~N}$, respectively, and the achieved thrust value is $2547 \mathrm{~N}$. Moreover, each thrust corresponds to the calculated value by using equation (8). At the point, when a LSG is driven near the limit of the driving range, the generation efficiency decreases because of the field weakening. Thus, in this examination, the LSG in which $2 \tau$ is $21.6 \mathrm{~mm}$ is suitable for the FPEG system.

From the above, the pole pitch is by selected by using the equations (6), (7), and (8) based on the combustion energy, the FPEG system is driven within the driving range. And the FPEG system can accommodate to various fuel. 


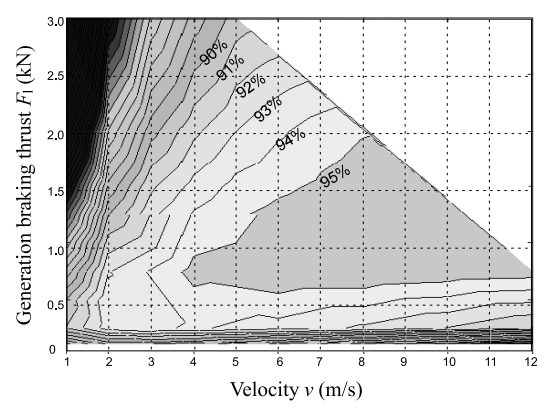

(a) $2 \tau=22.3 \mathrm{~mm}$

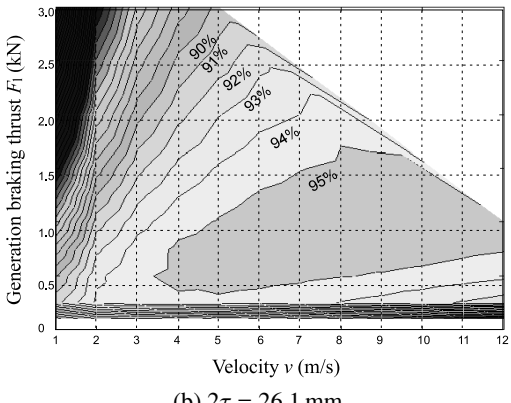

(b) $2 \tau=26.1 \mathrm{~mm}$

Fig. 11. Generation efficiency map of LSG (The pole pitch is modified)

\section{Conclusions}

In this study, the following results were obtained.

(1) Design of the LSG for the FPEG system

A configuration of the LSG for an FPEG was proposed for the ease of production. Magnetic saturation was not observed at the center of the armature teeth. Additionally, the static thrust versus armature current maintains linearity. A high generator efficiency exceeding $97 \%$ is provided in the lowthrust and high-velocity domains.

(2) Examination of driving range of the LSG

The pole pitch was selected based the combustion energy, and thus a suitable driving range was selected for the FPEG system. Therefore, combustion energy changes when fuel is used. Additionally, the FPEG system uses various fuel. Equations (6), (7), and (8) are used to design the LSG suitable for using fuel.

\section{References}

( 1 ) M. Graef, P. Treffinger, S.-E. Pohl, and F. Rinderknecht: "Investigation of a high efficient free piston linear generator with variable Stroke and variable compression ratio", The World Electric Vehicle Association Journal, Vol.1, pp.116-120 (2007)

( 2 ) F. Rinderknecht: "The linear generator as integral component of an energy converter for electric vehicles", MANGA European All-wheel Drive Congress Graz (2011)

( 3 ) F. Kock and F. Rinderknecht: "A high efficient energy converter for a hybrid vehicle concept—gas spring focused", EVER12 (2012)

( 4 ) R. Virsik, F. Rinderknecht, and H.E. Freidrich: "Free Piston Linear Generator and the development of a solid lubrication system", Proc. of ASME 2016 Int. Combustion Fall Technical Conf. (ICEF2016), 9362 (2016)

( 5 ) H. Kosaka, T. Akita, K. Moriya, N. Goto, and Y. Horita: "Development of Free Piston Engine Linear Generator System (First Report) Investigation of Fundamental Characteristics", Transaction of Society of Automotive Engineers of Japan, Vol.45, pp.683-689 (2014)

( 6 ) K. Moriya, N. Goto, H. Kosaka, T. Akita, Y. Horita, T. Umeno, and K. Nakakita: "Development of Free Piston Engine Linear Generator System
(Second Report) Investigation of Fundamental Characteristics", Transaction of Society of Automotive Engineers of Japan, Vol.45, No.4, pp.691-697 (2014)

( 7 ) K. Moriya, H. Kosaka, N. Goto, T. Akita, Y. Horita, and K. Nakakita: "Development of Free Piston Engine Linear Generator System (Third Report) Investigation of Fundamental Characteristics", 26th Internal Combustion Engine Symposium of Japan, 40-20158053 (2015)

( 8 ) J. Shin, T. Koseki, and H. Kim: "Thrust design of double-sided transverse flux type linear synchronous motor considering an effent of magnetic saturation", The papers of Joint Technical Meeting on "Rotating Machinery", "Linear Drives", and "Home and Consumer Appliances", IEE Japan, RM-12-066, LD-12-038, HCA-12-026 (2012)

Yuichiro Yamanaka (Student Member) received his B.E. degree

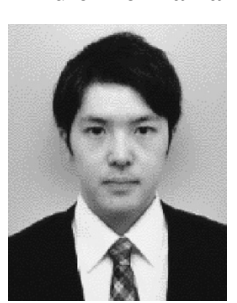
from Shinshu University, Nagano, Japan, in 2017. $\mathrm{He}$ is currently M.E. student at Shinshu University, Nagano. His research interests include linear synchronous generators.

Masami Nirei (Senior Member) is a professor with the Department

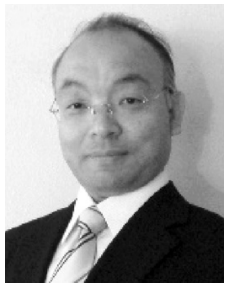
of Electronics and Computer Science, National Institute of Technology, Nagano College. He received B.E., M.E. and D.E. degree in electrical engineering from Shinshu University. He worked as engineer in Motor section at Gunma NEC from 1988-1990. He joined Shinshu University Hospital in 1990 as an assistant professor, and transferred to National Institute of Technology, Nagano College in 1991. His research work includes electromagnetic actuators and sensors, optimal design, numerical analysis. He is a member of the IEEE, the Magnetics Society of Japan and the Japan Society of Applied Electromagnetics and Mechanics.

Mitsuhide Sato (Student Member) received B.E. and M.E. degrees

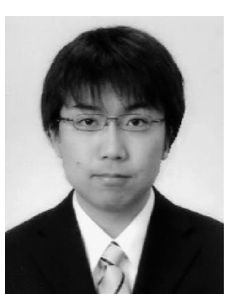
from Tohoku University, Sendai, Japan, in 2009 and 2011, respectively. From 2011 to 2015, he was an electrical engineer at TOSHIBA Corp., in Japan. Since 2015, he has been a Lecturer with Nagano Prefectural Institute of Technology, Ueda, Japan. Now he is also currently Ph.D. student at Shinshu University, Nagano, Japan. His research interests linear synchronous generator and power electronics. He is a student member of the Japan Society of Applied Electromagnetics and Mechanics (JSAEM)

Hironobu Murata (Non-member) received B.E. degree from Shinshu

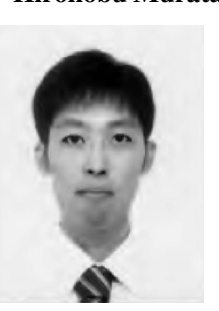
University in, Nagano, Japan, in 2017. Currently, he is M.E. student at Shinshu University, Nagano, Japan. His research interests include the linear motors. 
Yinggang Bu (Senior Member) received his B.S. degree in Electrical

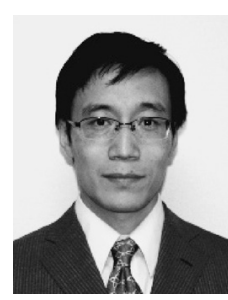
Engineering from TaiYuan University of Technology, China, in 2002. He received his M.S. and Ph.D. degrees in Electrical and Electronic Engineering from the Shinshu University, Japan, in 2006 and 2009, respectively. He is currently an associate professor in the Department of Engineering in Shinshu University, Japan. His research interests include linear motors and actuators, and wireless power transfer. $\mathrm{He}$ is a member of the IEEE and the Institute of Electrical

Engineers of Japan
Tsutomu Mizuno (Senior Member) received B.E. and M.E. degrees

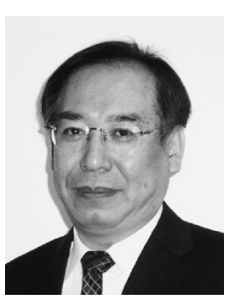
from Shinshu University, Nagano, Japan, in 1981 and 1983, respectively. From 1983 to 1996, he was an electrical engineer at AMADA CO., LTD. in Japan. Since 1996, he was an assistant professor, since 1999, he was associate professor and from 2011 he is a professor with the Department of Electrical and Computer Engineering, Shinshu University, Nagano, Japan. He holds a degrees of Doctor of Engineering from the Shinshu University. His research interests linear motor, linear actuator and Electromagnetic sensor. He is a member of the IEEE, the Magnetics Society of Japan and the Japan Society of Applied Electromagnetics and Mechanics (JSAEM). 